\title{
Longitudinal Transmission of Conflict Resolution Styles From Marital Relationships to Adolescent-Parent Relationships
}

\author{
Muriel D. Van Doorn, Susan J. T. Branje, and Wim H. J. Meeus \\ Utrecht University
}

\begin{abstract}
This study longitudinally investigated transmission: Can the way adolescents resolve conflicts with their parents be explained by the way parents resolve conflicts with each other? Questionnaires about conflict resolution styles were completed by 282 young adolescents (mean age $=13.2$ ) and their parents. Path analyses with cross-lagged effects indicated that transmission of conflict resolution styles from marital relationships to adolescent-parent relationships occurs: Conflict engagement and positive problem solving in marital relationships were significantly related to, respectively, conflict engagement and positive problem solving in adolescent-parent relationships 2 years later. No significant longitudinal effects emerged with regard to withdrawal. Thus, the study shows that the way marital conflicts are handled affects how adolescents deal with conflicts.
\end{abstract}

Keywords: conflict resolution, parent-adolescent relationships, marital relationships, transmission

Research indicates that marital relationships and parentchild relationships are linked to each other (Cox, Paley, \& Harter, 2001; Engfer, 1988; Erel \& Burman, 1995). Among the aspects of marital relationships, marital conflict has emerged as particularly significant with regard to its effects on parent-child relationships (Cummings, Goeke-Morey, \& Graham, 2002). Findings regarding the effect of marital conflict on parent-child relationships indicate that it is not whether but how parents fight that matters (Cummings et al., 2002; Cummings, Goeke-Morey, \& Papp, 2001). It has been suggested that exposure to parents who use constructive conflict resolution styles with each other has a different effect on children than exposure to parents who use hostile, emotionally destructive conflict resolution styles (Davies \& Cummings, 1994). In the current study, we investigated transmission of conflict resolution styles from marital relationships to adolescent-parent relationships over time. More specifically, we longitudinally investigated whether the way adolescents resolve conflicts with their parents can be explained by the way parents resolve conflicts with each other.

As early adolescence is a time of heightened parentadolescent conflict (Furman \& Buhrmester, 1992; Galambos \& Almeida, 1992; Laursen, Coy, \& Collins, 1998; Steinberg, 2001) and new ways of handling conflicts might evolve, our research focused on this age period. Ideally, the

Muriel D. Van Doorn, Susan J. T. Branje, and Wim H. J. Meeus, Research Centre Adolescent Development, Utrecht University, Utrecht, The Netherlands.

Correspondence concerning this article should be addressed to Muriel D. Van Doorn, Research Centre Adolescent Development, Utrecht University, P.O. Box 80.140, 3508 TC Utrecht, The Netherlands. E-mail: m.d.vandoorn@uu.nl renegotiation process starts in early adolescence, and parent-adolescent relationships start to become more egalitarian (Russel, Pettit, \& Mize, 1998). In this process, more mature ways of conflict resolution between parents and adolescents, characterized by more compromising and perspective taking, should develop. However, as conflict intensity (Laursen et al., 1998) and disengagement from conflicts (Laursen \& Collins, 1994) tend to increase during adolescence, conflict resolution with parents might also be characterized by fighting and arguing or withdrawal. The extent to which adolescents use compromising and perspective taking, fighting and arguing, or withdrawal in conflicts with their parents might depend on the extent to which parents use these conflict resolution styles in their marital relationship. The current study focused on various conflict resolution styles that adolescents could use in conflicts with their parents-namely, positive problem solving, conflict engagement, and withdrawal. Positive problem solving involves trying to understand the others' position and using constructive reasoning tactics to work out compromises. Conflict engagement involves being verbally abusive, angry, defensive, or attacking or losing self-control. Withdrawal involves avoiding the problem, avoiding talking, and becoming distant.

Different theoretical perspectives suggest a link between marital conflict resolution and adolescents' conflict resolution with their parents. First, according to social learning theory (Bandura, 1977), transmission goes through a process of modeling, in which adolescents observe their parents' attempts to resolve conflicts in the marital relationship and imitate those behaviors in their own conflicts. Second, observing how parents handle conflicts with each other is also likely to influence adolescents' internal working models of relationships (Bowlby, 1969; Fincham, Grych, \& 
Osborne, 1994), which could then have consequences for their own social interactions. Third, family systems theory regards the family as a social system, consisting of several subsystems (e.g., the marital subsystem, the parent-child subsystem). Each subsystem influences and is influenced by other subsystems (Minuchin, 1985). Moreover, according to family systems theory, families are hierarchically arranged, suggesting that parents' behaviors influence adolescents' behaviors more strongly than the reverse (e.g., Erel \& Burman, 1995). This suggests that the way parents resolve conflicts with each other influences the way adolescents resolve conflicts with their parents more strongly than the other way around. In sum, different perspectives predict that conflict resolution in marital relationships might influence the way adolescents resolve conflicts with their parents.

Several studies have found a relation between conflict resolution styles used in marital relationships and the same conflict resolution styles in parent-adolescent relationships (Noller, Feeney, Peterson, \& Sheehan, 1995; Noller, Feeney, Sheehan, \& Peterson, 2000; Reese-Weber, 2000; ReeseWeber \& Bartle-Haring, 1998; Rinaldi \& Howe, 2003). Together, these studies have found support for the relation between conflict resolution styles in marital and parentadolescent relationships for various conflict resolution styles: positive problem solving, conflict engagement, and withdrawal. However, whereas some of these studies have used only the adolescents' perception of conflict resolution styles for both marital and parent-adolescent relationships (Reese-Weber, 2000; Reese-Weber \& Bartle-Haring, 1998), others have used only the perception of the parents (Noller et al., 1995, 2000). Rinaldi and Howe measured both adolescents' and parents' perceptions of the way parents resolve conflicts with each other and with adolescents but only found a significant relation between the two subsystems when parents' perceptions were used. Therefore, the aforementioned studies have been unable to exclude reporter bias as an explanation for their results. The studies of Noller and colleagues (1995, 2000), however, have also found several significant relations when one parent rated conflict resolution in the marital relationship and the other parent rated conflict resolution in the parent-adolescent relationship, thereby strengthening their findings. In our study, we therefore used independent reports for measuring conflict resolution styles in the marital relationship and for measuring conflict resolution styles in the adolescent-parent relationship.

Although the aforementioned studies have provided support for the link between conflict resolution styles in marital relationships and parent-adolescent relationships, the crosssectional results do not allow conclusions regarding transmission over time. Moreover, in these studies parentadolescent conflict resolution has been measured as the combined score of adolescents' conflict resolution with parents and parents' conflict resolution with adolescents. Therefore, the link between conflict resolution styles in marital and parent-adolescent relationships could indicate both an effect on adolescents' conflict resolution styles with parents and an effect on parents' conflict resolution styles with adolescents. We explicitly wanted to examine whether transmission to adolescents' conflict resolution styles with parents occurs and thus investigated whether the conflict resolution styles adolescents use over time can be explained by the way parents handle marital conflicts. We call this transmission, that is, the process of transfer of mood, affect, or behavior from one person to another person (Bolger, DeLongis, Kessler, \& Wethington, 1989; Larson \& Almeida, 1999). Although sometimes this process has been labeled spillover (Erel \& Burman, 1995; Larson \& Almeida, 1999), according to the original definition, spillover refers only to the direct transfer of mood, affect, or behavior within one person from one setting to another (Bolger et al., 1989; Repetti, 1987) and is therefore more applicable to the link between fathers' conflict resolution styles with mothers and fathers' conflict resolution styles with adolescents as well as mothers' conflict resolution styles with fathers and mothers' conflict resolution styles with adolescents.

However, family systems theory also stresses the mutual influences between family relations. That is, it also highlights the importance of examining how parentadolescent relationships affect marital relationships (Cox et al., 2001) and suggests the possibility that the way adolescents resolve conflicts with their parents affects the way parents resolve conflicts with each other over time. Although the aforementioned studies that have found a link between marital and parent-adolescent relationships (Noller et al., 1995, 2000; Reese-Weber, 2000; ReeseWeber \& Bartle-Haring, 1998; Rinaldi \& Howe, 2003) all suggest that marital relationships influence parentadolescent relationships, they cannot, because of their cross-sectional design, rule out the possibility that parent-adolescent relationships influence marital relationships or that both subsystems influence each other.

In sum, we longitudinally investigated whether the way adolescents resolve conflicts with their parents can be explained by the way parents resolve conflicts with each other. Because we used a longitudinal design, we were able to draw conclusions about the direction of effects: Does the way parents resolve conflicts with each other influence the way adolescents resolve conflicts with their parents or vice versa, or do both family subsystems influence each other? We investigated how positive problem solving, conflict engagement, and withdrawal in marital relationships are related to, respectively, positive problem solving, conflict engagement, and withdrawal in adolescent-parent relationships 2 years later. We used independent perspectives, as marital conflict resolution styles were measured by both fathers' and mothers' perceptions, and adolescent-parent conflict resolution styles were measured by adolescents' perceptions of their conflict resolution styles with both fathers and mothers. We tested whether the conflict resolution styles parents use with each other were significantly related to the conflict resolution styles adolescents use with their parents over time. Moreover, we tested whether the path from marital conflict resolution to adolescent-parent conflict resolution was significantly stronger than the reverse path. 
Method

\section{Participants}

Participants in this study came from the family sample of the CONAMORE longitudinal study (Conflict and Management of Relationships; Meeus et al., 2004). In the main study of CONAMORE, 938 young adolescents (mean age $=12.4$ years, $S D=0.6$, range $=10-15$ years) and 393 middle adolescents (mean age $=16.7$ years, $S D=0.8$, range $=16-20$ years) from 12 high schools located in the province of Utrecht, the Netherlands, annually filled out a battery of questionnaires at school. At the first measurement, the Dutch young adolescents received a letter including an invitation to participate with both parents during annual home visits as well. Of the families invited, 491 families initially agreed to participate. Because of our restriction of including only twoparent Dutch families, 90 one-parent families who agreed to participate were not able to take part in this additional research project. Of the remaining 401 families, 323 families were randomly selected to participate from Wave 2 onward. We refer to this sample as the family sample. Of these 323 families, 320 families participated at Wave 4 (attrition was less than 1\%). In our analyses we used only families with complete data on two measurement waves over a 2-year time interval, so the final sample consisted of 282 adolescents and their parents. We refer to Wave 2 as Time 1 and to Wave 4 as Time 2.

Of the adolescents who participated in the family sample, 138 were boys $(48.9 \%)$. At the first measurement wave of the family sample, the mean age of the adolescents was 13.2 years $(S D=0.5$, range $=11-15$ years $)$; the mean age of the fathers and mothers was, respectively, 46.9 years $(S D=5.1$, range $=35-65)$ and 44.2 years $(S D=4.1$, range $=34-55$ years). Most adolescents named Dutch as their main ethnic identity (99.3\%) and lived with both parents (98.6\%).

Adolescents were relatively highly educated with approximately $50 \%$ of the adolescents at schools preparing for university, $35 \%$ of the adolescents at schools preparing for higher education, and $15 \%$ of the adolescents at schools preparing for blue-collar work (because some classes are combination classes of different school levels, exact numbers cannot be provided). The educational level of the fathers and mothers could be differentiated as $27.3 \%$ and $32.0 \%$ low-middle, and $72.7 \%$ and $68.0 \%$ high, respectively.

Analyses were performed to test whether there were differences between the adolescents who participated in the family sample and those who did not. When selecting the comparison group, we controlled for the fact that only adolescents from intact Dutch families were invited to take part in the family sample. A multivariate analysis of variance showed no differences between participants in the family sample and nonparticipants on age, gender, and adolescents' conflict resolution styles with fathers and mothers at Wave 2, $F(8,634)=2.20, p>.01$.

\section{Procedure}

Before the study, both adolescents and their parents received written information and, if the adolescent wished to participate, were required to provide written informed consent. Interviewers visited the schools and asked participating adolescents to gather in classrooms to fill out a questionnaire. Interviewers also visited the families at home. During these home visits, adolescents filled out an additional questionnaire and both parents also filled out a questionnaire. The adolescents and their parents were instructed to fill out the questionnaire independent of each other. Results were processed anonymously. Each wave, families received €27 (\$35.95), for participating and adolescents received an additional amount of $€ 10$ (\$13.32), for participating at school.

\section{Measures of Conflict Resolution Styles}

Conflict resolution styles were measured by Kurdek's Conflict Resolution Style Inventory (Kurdek, 1994). The scores on three conflict resolution styles were used for this study: conflict engagement, positive problem solving, and withdrawal. Fathers and mothers rated the conflict resolution styles they used in conflicts with each other at both measurement waves. Adolescents rated the conflict resolution styles they used in conflicts with both fathers and mothers, also at both measurement waves. Each style was measured by five items, and these items were rated on a 5-point Likert-type scale with response options ranging from never to always. Conflict engagement was measured by items such as "getting furious and losing my temper," and "letting myself go and saying things I do not really mean." Positive problem solving involved making compromises (e.g., "negotiating and trying to find a solution that is mutually acceptable") and discussing the conflict effectively (e.g., "sitting down and discussing the differences of opinion"). Items used to measure withdrawal were, for example, "not listening anymore," "refusing to talk any longer," and "withdrawing from the situation."

Factor analyses showed the expected three-factor structure with all loadings greater than .36, both for marital and adolescent-parent conflict resolution styles. With regard to the marital relationship, this factor structure was also found by Kurdek (1994). The temporal stability of the conflict resolution styles in the marital and adolescent-parent relationship was moderately high, ranging from .48 to .72 (see Table 1). The stability coefficients that were found in the marital relationship are comparable to previous findings (Kurdek, 1994), although there the 1-year stability was computed. Cronbach's alphas ranged from .85 to $.94, .76$ to .84 , and .78 to .86 for adolescents' conflict resolution with parents on positive problem solving, conflict engagement, and withdrawal, respectively. For fathers' and mothers' conflict resolution styles with each other, Cronbach's alphas ranged from .85 to $.88, .74$ to .79 , and .81 to .83 on positive problem solving, conflict engagement, and withdrawal, respectively. 
Table 1

Intercorrelations Between Indicators of Conflict Resolution Styles in Marital Relationships and Adolescent-Parent Relationships at Time 1 (T1) and Time 2 (T2)

Variable

12

2

$3 \quad 4 \quad 5$

$5 \quad 6$

6

Positive problem solving

1. Mothers with fathers, T1

2. Fathers with mothers, T1

3. Adolescents with mothers, T1

4. Adolescents with fathers, T1

5. Mothers with fathers, T2

6. Fathers with mothers, T2

7. Adolescents with mothers, T2

8. Adolescents with fathers, T2

$\begin{array}{ll}. \overline{24}^{* * *} & -10 \\ .15^{*} & .10 \\ .07 & .11 \\ .64^{* * *} & .34^{* * *} \\ .20^{* * *} & .64^{* *} \\ .17^{* * *} & .17^{* *} \\ .20^{* * *} & .22^{* *}\end{array}$
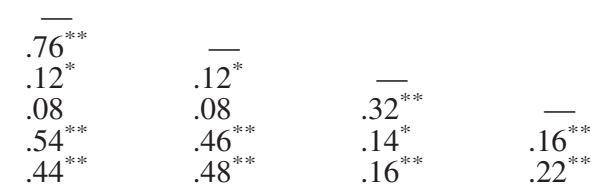

Conflict engagement

1. Mothers with fathers, T1

2. Fathers with mothers, T1

3. Adolescents with mothers, T1

4. Adolescents with fathers, T1

5. Mothers with fathers, T2

6. Fathers with mothers, T2

7. Adolescents with mothers, T2

8. Adolescents with fathers, T2

$\begin{array}{ll}. \overline{.0}^{* * *} & \\ .11 & .06 \\ .11 & .05 \\ .68^{* * *} & .27^{* * *} \\ .36^{* *} & .72^{* *} \\ .13^{* *} & .13^{*} \\ .07 & .12^{*}\end{array}$

$.81^{* *}$
.08
.02
$.59^{* *}$
$.44^{* *}$

$\begin{array}{ll}.02 & \\ .05 & \\ .54^{* * *} & .29^{* * *} \\ .50^{* * *} & .14^{* *}\end{array}$

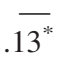

.13
.09 $.74^{* * *}$

Withdrawal

1. Mothers with fathers, T1

2. Fathers with mothers, T1

3. Adolescents with mothers, T1

4. Adolescents with fathers, T1

5. Mothers with fathers, T2

6. Fathers with mothers, T2

7. Adolescents with mothers, T2

8. Adolescents with fathers, T2

${ }^{*} p<.05 . \quad{ }^{* * *} p<.01$.

$\begin{array}{ll}.30^{* * *} & - \\ .19^{* * *} & .11 \\ .15^{* *} & .10 \\ .60^{* *} & .29^{* *} \\ .23^{* * *} & .63^{* *} \\ .15^{*} & .05 \\ .19^{* * *} & .09\end{array}$

$\begin{array}{ll}\overline{.11} & \\ .10 & .78^{* *} \\ .29^{* *} & .23^{* *} \\ .63^{* *} & .04^{* *} \\ .05 & .52^{* *} \\ .09 & .48^{* *}\end{array}$
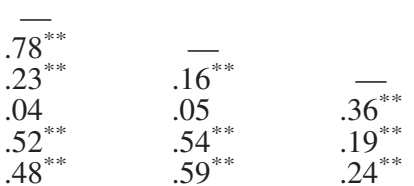

.$\overline{04}$

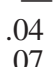

.04
.07

$.24^{*}$

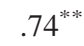

\section{Results}

To answer our research question, we performed path analyses with cross-lagged effects for each conflict resolution style separately by means of structural equation modeling using AMOS (Arbuckle, 2003). A latent model was constructed for each conflict resolution style separately (i.e., positive problem solving, conflict engagement, and withdrawal). Conflict resolution in marital relationships was measured as a latent variable with fathers' conflict resolution style with mothers and mothers' conflict resolution style with fathers as indicators. To ensure the same influence of fathers' and mothers' style on the construct, we fixed all factor loadings to 1 . Conflict resolution of adolescents with parents was measured as a latent construct with adolescents' conflict resolution style with mothers and fathers as indicators. Again, all factor loadings were fixed to 1 to ensure equal importance of the conflict resolution style in adolescent-father and adolescent-mother relationships. Corresponding measurement errors of each observed variable at Time 1 and Time 2 were allowed to correlate across the two time points. For example, the error of mothers' conflict resolution style with fathers at Time 1 was allowed to correlate with the error of mothers' conflict resolution style with fathers at Time 2 . The conceptual model is shown in Figure 1. The correlations between the indicators of marital and adolescent-parent relationships at each measurement wave are presented in Table 1.

To evaluate the fit of each model, we used the goodnessof-fit index (GFI), the nonnormed fit index (NNFI), and the root-mean-square error of approximation (RMSEA). For values of GFI and NNFI, values above .90 indicate acceptable fit and values above .95 indicate good fit ( $\mathrm{Hu} \&$ Bentler, 1999). RMSEA values up to .06 represent a close fit of the model. The coefficients in the figures are standardized estimates.

Figure 2 represents the maximum-likelihood results of the model for positive problem solving. This model provided a good fit to the data. Compared with a model without the cross-lagged paths, this model provided a significantly better fit, $\Delta \chi^{2}(2)=10.06, p<.05$. The results of this model showed a very high stability of positive problem solving in marital relationships over the two measurement waves $(\beta=$ $.96, p<.01)$. The stability of positive problem solving in adolescent-parent relationships was moderately high $(\beta=$ $.53, p<.01)$. At Time 1, a significant relation was found between positive problem solving in marital relationships and positive problem solving in adolescent-parent relationships $(r=.25, p<.05)$. Moreover, positive problem 


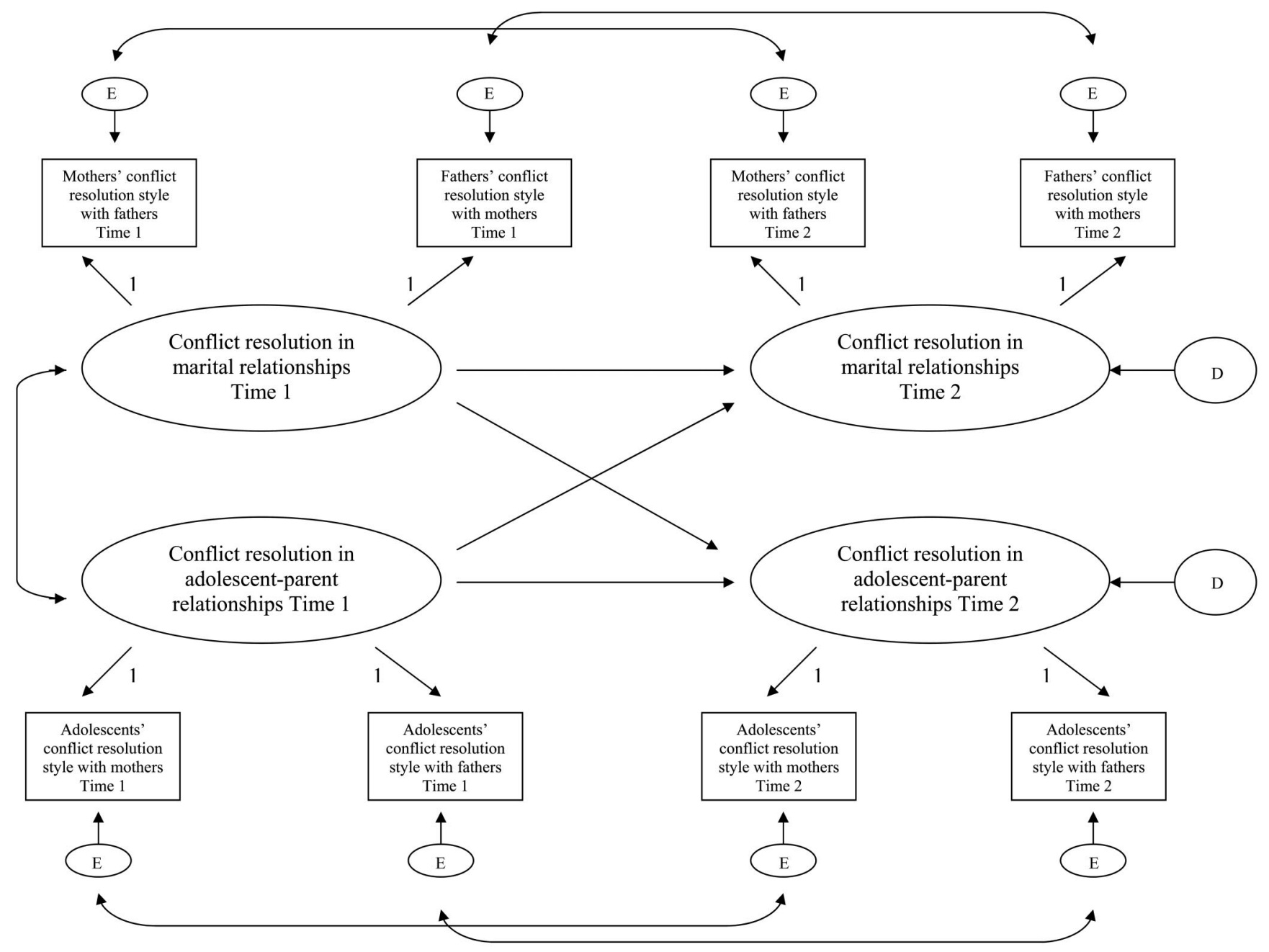

Figure 1. Model estimated to assess the longitudinal association between conflict resolution styles in marital and adolescent-parent relationships. $\mathrm{E}=$ measurement error; $\mathrm{D}=$ disturbance.

solving in marital relationships was significantly related to positive problem solving in adolescent-parent relationships 2 years later $(\beta=.24, p<.01)$. The path from positive problem solving in adolescent-parent relationships to positive problem solving in marital relationships was not significant $(\beta=-.05)$. Critical ratio $(\mathrm{CR})$ comparisons of these coefficients showed that the path from marital to adolescent-parent relationships was significantly stronger than the reverse path $(\mathrm{CR}=-2.900, p<.01$, one-tailed). Thus, positive problem solving of adolescents with parents can be explained over time by the use of positive problem solving by parents in conflicts with each other.

The results for the relation between conflict engagement in marital relationships and adolescent-parent relationships are shown in Figure 3. When we tested this model, a negative disturbance term for marital conflict engagement appeared. Because this value is not possible, we decided to set this value to .01. This model provided a good fit to the data. Compared with a model without the cross-lagged paths, this model provided a significantly better fit,
$\Delta \chi^{2}(2)=6.694, p<.01$. Again, the results of this model showed a high stability of the conflict resolution style used in marital relationships over the two measurement points $(\beta=.95, p<.01)$. The stability of conflict engagement in adolescent-parent relationships was moderately high $(\beta=$ $.61, p<.01)$. At Time 1 , no significant relation was found between conflict engagement in marital relationships and conflict engagement in adolescent-parent relationships $(r=$ .15). However, conflict engagement in marital relationships was significantly related to conflict engagement in adolescent-parent relationships 2 years later $(\beta=.17, p<$ $.05)$. The reverse path, from adolescent-parent conflict engagement to marital conflict engagement, was not significant $(\beta=-.07)$. Furthermore, critical ratio comparisons of these coefficients indicated that the path from marital to adolescent-parent relationships was significantly stronger than the reverse path $(\mathrm{CR}=-2.465, p<.01$, one-tailed $)$.

Figure 4 shows the results of the model for withdrawal. As with the other two models, this model provided a good fit to the data. However, compared with a model without the 


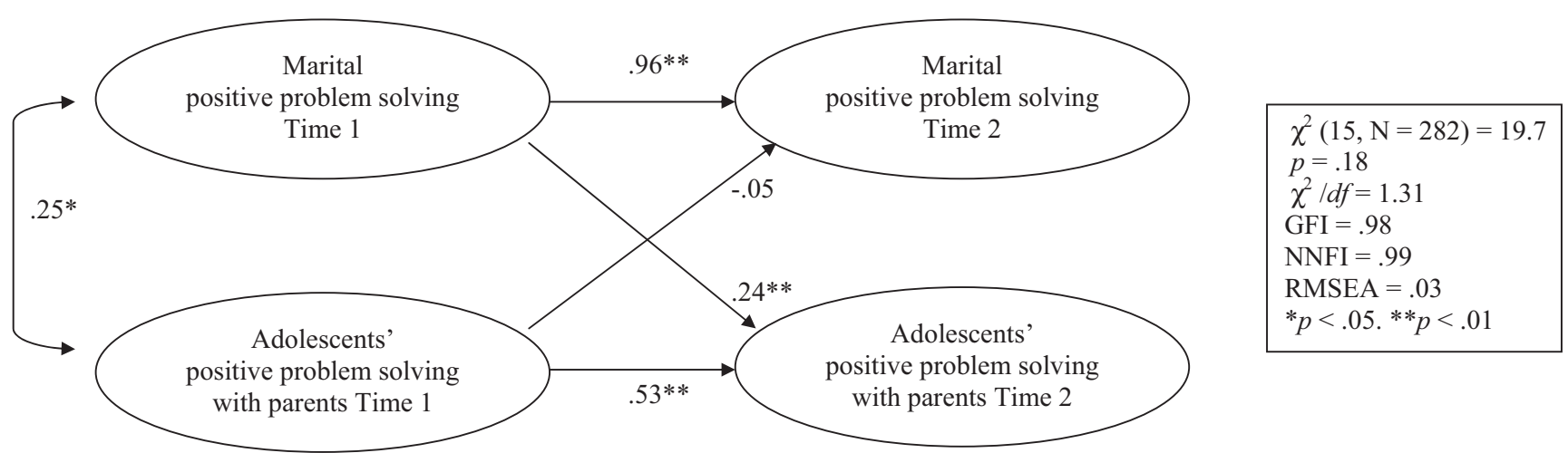

Figure 2. Relation between positive problem solving in marital and adolescent-parent relationships. GFI = goodness-of-fit index; NNFI = nonnormed fit index; RMSEA = root-mean-square error of approximation.

cross-lagged paths, this model did not provide a significantly better fit, $\Delta \chi^{2}(2)=1.409, p>.05$. Nevertheless, in order to be able to compare the different conflict resolution styles, we report the results of the model with the crosslagged paths. Stability of withdrawal in marital and adolescent-parent relationships was, respectively, very high and moderately high $(\beta=.81, p<.01$, and $\beta=.64, p<$ $.01)$. The relation between withdrawal in marital relationships and adolescent-parent relationships was significant at Time $1(r=.28, p<.01)$. However, withdrawal in marital relationships was not significantly related to withdrawal in adolescent-parent relationships 2 years later $(\beta=.09)$. The relation between withdrawal in adolescent-parent relationships and withdrawal in marital relationships 2 years later was also not significant $(\beta=.00)$.

\section{Discussion}

The purpose of the present study was to investigate whether the way adolescents resolve conflicts with their parents could be explained by the way parents resolve conflicts with each other or, in other words, whether trans- mission of conflict resolution styles from marital to adolescent-parent relationships occurred. The results clearly show that the use of positive problem solving and conflict engagement by adolescents in parent-adolescent relationships can be explained longitudinally by the use of, respectively, positive problem solving and conflict engagement in marital relationships. Although it has been suggested that the negative always has more impact on human behavior than the positive (Baumeister, Bratslavsky, Finkenauer, \& Vohs, 2001), we found that transmission occurred for both positive and negative conflict resolution.

To our knowledge, this is the first study that examined the relation between marital conflict resolution styles and adolescent-parent conflict resolution styles longitudinally. Our study found support for the notion that conflict resolution styles in marital relationships influence adolescents' conflict resolution styles with parents over time after controlling for concurrent relations between conflict resolution styles in marital relationships and adolescent-parent relationships. By focusing on adolescents' own conflict resolution styles in relationships with parents, our results allow us

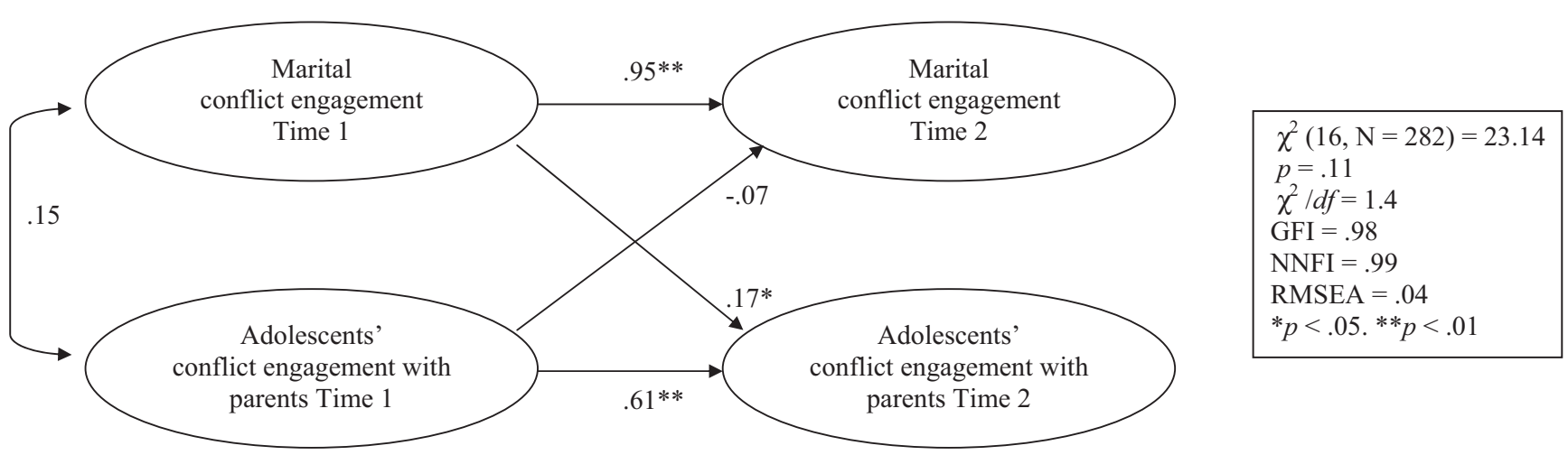

Figure 3. Relation between conflict engagement in marital and adolescent-parent relationships. $\mathrm{GFI}=$ goodness-of-fit index; NNFI = nonnormed fit index; RMSEA = root-mean-square error of approximation. 


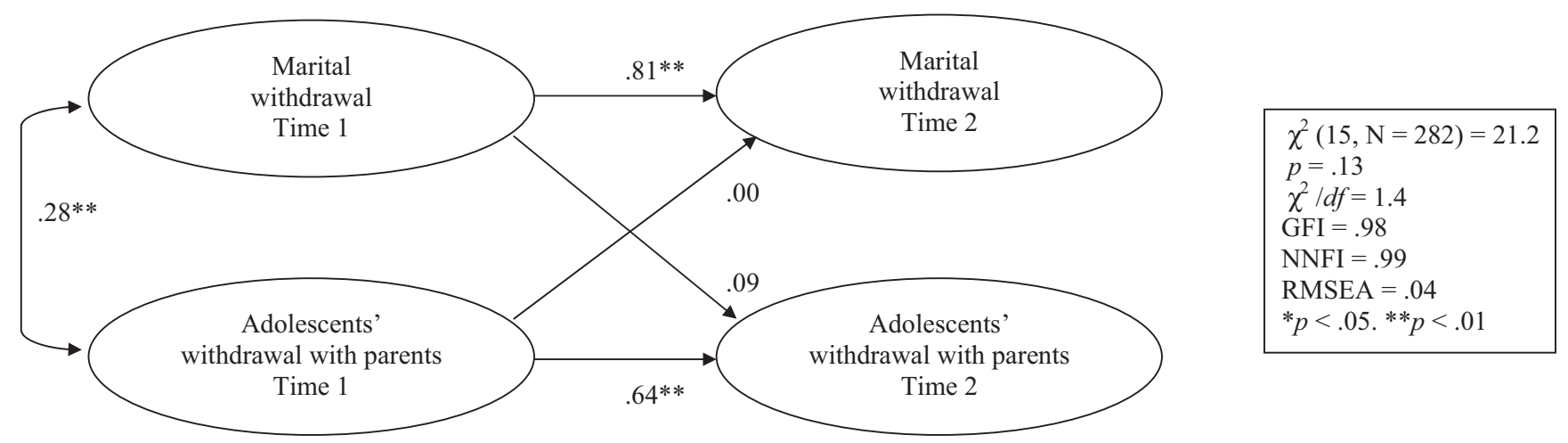

Figure 4. Relation between withdrawal in marital and adolescent-parent relationships. GFI = goodness-of-fit index; NNFI = nonnormed fit index; RMSEA = root-mean-square error of approximation.

to conclude that the effects found from marital relationships to adolescents' relationships with parents over time are transmission effects from parents to adolescents and not spillover effects of parents from one relational context to another. The use of independent reports for marital conflict resolution and adolescent conflict resolution further strengthens this conclusion and ensures that reporter bias could not explain the relation we found.

Our results might be explained by family systems theory, which indicates that subsystems within the family are hierarchically arranged, with the largest influence being that of the marital relationship. Our finding that marital conflict resolution styles influence adolescent-parent conflict resolution styles more strongly than the other way around is in line with this hierarchical organization. However, family systems theory also emphasizes the importance of bidirectionality, and therefore the idea that adolescents' conflict resolution styles with parents might also influence the way parents resolve conflicts with each other (Cox et al., 2001). However, when it comes to conflict resolution styles, we found no indication for bidirectionality between the marital and adolescent-parent subsystem. The consequences of marital conflict for children's and adolescents' adjustment have been extensively examined (for reviews, see Davies \& Cummings, 1994; Grych \& Fincham, 1990; Zimet \& Jacob, 2001). Our research extends these results, in that we found that conflict resolution styles in marital relationships also have consequences for the way adolescents handle conflicts with their parents over time. An alternative explanation for our findings may be that the effects we found are, at least to some extent, developmental in nature. It is possible that the genetic resemblance to parents becomes apparent in adolescence (e.g., Plomin et al., 1993).

Although we distinguished transmission from spillover effects, spillover effects might still play a role in explaining the transmission of conflict resolution styles from marital to adolescent-parent relationships, albeit in a more indirect way. The fact that marital conflict spills over to parents' behavior in the parent-child relationship has been widely acknowledged (Erel \& Burman, 1995; Krishnakumar \&
Buehler, 2000). In our study, it is possible that when parents use a certain resolution style with each other during conflicts, this might spill over to conflict resolution styles fathers and mothers use during conflicts with their adolescents. As a consequence, adolescents might reciprocate that same resolution style. Thus, although we distinguished the conflict resolution styles of adolescents and parents, the conflict resolution styles parents use in conflicts with their adolescents might still mediate the relation we found between conflict resolution styles in marital relationships and adolescent-parent relationships.

No significant result emerged for the conflict resolution style characterized by withdrawal. Although two studies (Reese-Weber \& Bartle-Haring, 1998; Rinaldi \& Howe, 2003) found a significant relation between withdrawal in marital and parent-adolescent relationships, we found this relation only concurrently and were unable to find this relation longitudinally. An explanation for this nonsignificant result regarding transmission of withdrawal might be that withdrawal in the marital relationship is less visible for adolescents than the other conflict resolution styles and thus it is less likely that adolescents imitate this style or construct internal working models of this style. Withdrawal might also conceal the underlying conflict. For adolescents, it might appear as if their parents have no conflicts, and thus it is also less probable that this conflict resolution style will be transmitted to adolescent-parent relationships. Results of a meta-analysis by Krishnakumar and Buehler (2000) indicate that the spillover effect from marital conflict to parenting behaviors was the strongest for overt conflict between parents. This suggests that more covert conflict resolution styles by parents, like withdrawal, might affect parentadolescent relationships less strongly. The same might be true for transmission of covert conflict resolution styles.

Although our study provides interesting findings regarding the transmission of conflict resolution styles between family subsystems, it also has a number of limitations. First, we used self-reports only to assess conflict resolution styles. More objective data would be obtained when using, for instance, observations or reports from more than one per- 
son. Second, by focusing on multiple conflict resolution styles at the same time, we were unable to examine whether transmission of conflict resolution styles that were predominantly used occurs. However, research on adolescents' conflicts with parents found that the use of several conflict resolution styles by the same person is quite common (Rubenstein \& Feldman, 1993). Third, future research should extend our findings to other types of families, for example, less well-functioning families, and should consider transmission of conflict resolution styles to other family subsystems, for example, sibling relationships. There is an indication that transmission from parent-adolescent to sibling relationships might occur, for these family subsystems have been found to be related (Noller et al., 1995, 2000; Reese-Weber, 2000; Rinaldi \& Howe, 2003). Fourth, future research might differentiate transmission of conflict resolution styles for the four dyads, that is, the daughtermother, daughter-father, son-mother, and son-father dyad. Finally, it might be interesting to investigate the moderating role of both marital and parent-adolescent conflict on the transmission process.

In conclusion, the current study clearly shows that the way adolescents resolve conflicts with parents can be explained longitudinally by the way parents resolve conflicts with each other. When parents use more positive problem solving during marital conflicts, adolescents will also use this style more when facing conflicts with parents. On the other hand, when parents use more conflict engagement during marital conflicts, they will also encounter conflict engagement by their adolescents in their conflicts. Thus, for parents, it is an important lesson to handle conflicts better for the sake of their children and for themselves. Moreover, by focusing on adolescent conflict resolution styles in parent-adolescent relationships, we were able to provide a more accurate picture of how marital and parent-adolescent relationships are related. This increases our knowledge about the mechanism behind the relation of conflict resolution styles between family subsystems.

\section{References}

Arbuckle, J. L. (2003). AMOS 5.0.1. [Computer software]. Chicago: SmallWaters.

Bandura, A. (1977). Social learning theory. Englewood Cliffs, NJ: Prentice Hall.

Baumeister, R. F., Bratslavsky, E., Finkenauer, C., \& Vohs, K. D. (2001). Bad is stronger than good. Review of General Psychology, 5, 323-370.

Bolger, N., DeLongis, A., Kessler, R. C., \& Wethington, E. (1989). The contagion of stress across multiple roles. Journal of Marriage and the Family, 51, 175-183.

Bowlby, J. (1969). Attachment and loss: Vol. 1. Attachment. London: Hogarth Press.

Cox, M. J., Paley, B., \& Harter, K. (2001). Interparental conflict in parent-child relationships. In J. H. Grych \& F. D. Fincham (Eds.), Interparental conflict and child development: Theory, research, and applications (pp. 249-272). New York: Cambridge University Press.

Cummings, E. M., Goeke-Morey, M. C., \& Graham, M. A. (2002). Interparental relations as a dimension of parenting. In J. G. Borkowski, S. L. Ramey, \& M. Bristol-Power (Eds.), Parenting and the child's world: Influences on academic, intellectual, and socio-emotional development (pp. 251-263). Mahwah, NJ: Erlbaum.

Cummings, E. M., Goeke-Morey, M. C., \& Papp, L. M. (2001). Couple conflict, children, and families: It's not just you and me, babe. In A. Booth, A. C. Crouter, \& M. Clements (Eds.), Couples conflict (pp. 117-147). Mahwah, NJ: Erlbaum.

Davies, P. T., \& Cummings, E. M. (1994). Marital conflict and child adjustment: An emotional security hypothesis. Psychological Bulletin, 116, 387-411.

Engfer, A. (1988). The interrelatedness of marriage and the mother-child relationship. In R. A. Hinde \& J. Stevenson-Hinde (Eds.), Relationships within families: Mutual influences (pp. 104-118). Oxford, England: Clarendon Press.

Erel, O., \& Burman, B. (1995). Interrelatedness of marital relations and parent-child relations: A meta-analytic review. Psychological Bulletin, 118, 108-132.

Fincham, F. D., Grych, J. H., \& Osborne, L. N. (1994). Does marital conflict cause child maladjustment? Directions and challenges for longitudinal research. Journal of Family Psychology, 8, 128-140.

Furman, W., \& Buhrmester, D. (1992). Age and sex differences in perceptions of networks of personal relationships. Child Development, 63, 103-115.

Galambos, N. L., \& Almeida, D. M. (1992). Does parentadolescent conflict increase in early adolescence? Journal of Marriage and the Family, 54, 737-747.

Grych, J. H., \& Fincham, F. D. (1990). Marital conflict and children's adjustment: A cognitive-contextual framework. Psychological Bulletin, 108, 267-290.

Hu, L. T., \& Bentler, P. M. (1999). Cut-off criteria for fit indexes in covariance structure analysis: Conventional criteria versus new alternatives. Structural Equation Modeling, 6, 1-55.

Krishnakumar, A., \& Buehler, C. (2000). Interparental conflict and parenting behaviors: A meta-analytic review. Family Relations, 29, 25-44.

Kurdek, L. A. (1994). Conflict resolution styles in gay, lesbian, heterosexual nonparent, and heterosexual parent couples. Journal of Marriage and the Family, 56, 705-722.

Larson, R. W., \& Almeida, D. M. (1999). Emotional transmission in the daily lives of families: A new paradigm for studying family process. Journal of Marriage and the Family, 61, 5-20.

Laursen, B., \& Collins, W. A. (1994). Interpersonal conflict during adolescence. Psychological Bulletin, 115, 197-209.

Laursen, B., Coy, K. C., \& Collins, W. A. (1998). Reconsidering changes in parent-child conflict across adolescence: A metaanalysis. Child Development, 69, 817-832.

Meeus, W. H. J., Akse, J., Branje, S. J. T., Ter Bogt, T., Delsing, M., Van Doorn, M. D., et al. (2004). Codebook of the research project CONflict And Management Of RElationships (CONAMORE). Unpublished manuscript, Utrecht University, The Netherlands.

Minuchin, P. (1985). Families and individual development: Provocations from the field of family therapy. Child Development, 56, 289-302.

Noller, P., Feeney, J. A., Peterson, C., \& Sheehan, G. (1995). Learning conflict patterns in the family: Links between marital, parental and sibling relationships. In T. Socha \& G. Stamp (Eds.), Parents, children and communication: Frontiers of theory and research (pp. 273-298). Hillsdale, NJ: Erlbaum.

Noller, P., Feeney, J. A., Sheehan, G., \& Peterson, C. (2000). Marital conflict patterns: Links with family conflict and family members' perceptions of one another. Personal Relationships, 7, 79-94. 
Plomin, R., Emde, R. N., Braungart, J. M., Campos, J., Corley, R., Fulker, D. W., et al. (1993). Genetic change and continuity from fourteen to twenty months: The MacArthur Longitudinal Twin Study. Child Development, 64, 1354-1376.

Reese-Weber, M. (2000). Middle and late adolescents' conflict resolution skills with siblings: Associations with interparental and parent-adolescent conflict resolution. Journal of Youth and Adolescence, 29, 697-711.

Reese-Weber, M., \& Bartle-Haring, S. (1998). Conflict resolution styles in family subsystems and adolescent romantic relationships. Journal of Youth and Adolescence, 27, 735-752.

Repetti, R. L. (1987). Linkages between work and family roles. In S. Oskamp (Ed.), Family processes and problems: Social psychological aspects (pp. 98-127). Newbury Park, CA: Sage.

Rinaldi, C. M., \& Howe, N. (2003). Perceptions of constructive and destructive conflict within and across family subsystems. Infant and Child Development, 12, 441-459.
Rubenstein, J. L., \& Feldman, S. S. (1993). Conflict-resolution behavior in adolescent boys: Antecedents and adaptational correlates. Journal of Research on Adolescence, 3, 41-66.

Russel, A., Pettit, G. S., \& Mize, J. (1998). Horizontal qualities in parent-child relationships: Parallels with and possible consequences for children's peer relationships. Developmental Review, $18,313-352$.

Steinberg, L. (2001). We know some things: Parent-adolescent relationships in retrospect and prospect. Journal of Research on Adolescence, 11, 1-19.

Zimet, D. M., \& Jacob, T. (2001). Influences of marital conflict in child adjustment: Review of theory and research. Clinical Child and Family Psychology Review, 4, 319-335.

Received February 6, 2006

Revision received May 11, 2006

Accepted May 25, 2006

\section{Low Publication Prices for APA Members and Affiliates}

Keeping you up-to-date. All APA Fellows, Members, Associates, and Student Affiliates receive-as part of their annual dues-subscriptions to the American Psychologist and APA Monitor. High School Teacher and International Affiliates receive subscriptions to the APA Monitor, and they may subscribe to the American Psychologist at a significantly reduced rate. In addition, all Members and Student Affiliates are eligible for savings of up to $60 \%$ (plus a journal credit) on all other APA journals, as well as significant discounts on subscriptions from cooperating societies and publishers (e.g., the American Association for Counseling and Development, Academic Press, and Human Sciences Press).

Essential resources. APA members and affiliates receive special rates for purchases of APA books, including the Publication Manual of the American Psychological Association, and on dozens of new topical books each year.

Other benefits of membership. Membership in APA also provides eligibility for competitive insurance plans, continuing education programs, reduced APA convention fees, and specialty divisions.

More information. Write to American Psychological Association, Membership Services, 750 First Street, NE, Washington, DC 20002-4242. 